\title{
BET Inhibitor CPI-0610
}

National Cancer Institute

\section{Source}

National Cancer Institute. BET Inhibitor CPI-0610. NCI Thesaurus. Code C111901.

A small molecule inhibitor of the Bromodomain and Extra-Terminal (BET) family of proteins, with potential antineoplastic activity. Upon administration, the BET inhibitor CPI0610 binds to the acetylated lysine recog nition motifs on the bromodomain of BET proteins, thereby preventing the interaction between the BET proteins and acetylated histone peptides. This disrupts chromatin remodeling and gene expression. Prevention of the expression of certain growth-promoting genes may lead to an inhibition of tumor cell growth. Characterized by a tandem repeat of two bromodomains at the $\mathrm{N}$-terminus, the BET proteins (BRD2, BRD3, BRD4 and BRDT) are transcriptional regulators that play an important role during development and cellular growth. 